\title{
Gender Differences in Any-Source Caffeine and Energy Drink Use and Associated Adverse Health Behaviors
}

\author{
Pamela Dillon, PharmD, ${ }^{1}$ Sydney Kelpin, $M S^{2}{ }^{2}$ Kenneth Kendler, MD, ${ }^{3-5}$ \\ Leroy Thacker, $\mathrm{PhD},{ }^{6}$ Danielle Dick, $\mathrm{PhD},{ }^{2,5}$ and Dace Svikis, $\mathrm{PhD}^{2,7}$
}

\begin{abstract}
Background: The majority of college students report caffeine use with many using caffeine daily. Energy drink (ED) use, in particular, is common among college students, and numerous studies link these heavily caffeinated drinks to a variety of adverse consequences including substance use and risky behaviors. However, little is known about correlations between any-source caffeine use and other substance use and problems. The purpose of this study was to evaluate patterns of caffeine use and examine the relationships between caffeine, in general, and EDs specifically, and adverse health behaviors in college students.

Methods: We used data from a longitudinal study of alcohol use and health-related outcomes to assess caffeine, alcohol, nonprescription drug, and tobacco use and symptoms of alcohol dependence in 1958 freshmen from a mid-Atlantic university during Fall 2012. We compared adverse health behaviors between caffeine users and nonusers and ED users and nonusers. Data were evaluated separately in men and women. Results: While women reported significantly more caffeine use than men, men reported more ED use. EDs, regardless of frequency of use, were associated with all adverse health behaviors, but only in female students. Similarly, daily any-source caffeine use was significantly associated with alcohol, nonprescription drug, and tobacco use in female students, but in men, the association was less robust.

Conclusions: This research shows that caffeine use is prevalent among college students, and, in female students, is associated with alcohol, nonprescription drug, and tobacco use and alcohol dependence symptoms. Interventions aimed at promoting healthy behaviors may be especially useful in this population.
\end{abstract}

Keywords: caffeine, energy drinks, substance use, gender

\section{Introduction}

C AFFEINE USE IS UBIQUITOUS with an estimated $85 \%$ of the United States adult population reporting daily use. $^{1}$ About $75 \%$ of U.S. adolescents and young adults report caffeine use any given day. ${ }^{2}$ College students are a unique group of adolescents and young adults with unique patterns of substance use, ${ }^{3,4}$ and research shows that $89-95 \%$ of them consume caffeine regularly..$^{5-7}$

While the American Academy of Pediatrics recommends that adolescents consume no more than $100 \mathrm{mg}$ caffeine/day ${ }^{8}$ the Food and Drug Administration reports that consuming up to $400 \mathrm{mg}$ caffeine/day is not associated with adverse events in healthy adults. ${ }^{9}$ Consumption of 500-600 mg caffeine per day, however, is associated with adverse physical and psychological consequences including headaches, insomnia, nervousness, restlessness, irritability, gastrointestinal distress, tachycardia, and muscle tremors. ${ }^{10} \mathrm{Up}$ to $13 \%$ of caffeine users experience clinically significant withdrawal symptoms without continuous use, most commonly headache. ${ }^{11}$

Historically, caffeine was consumed by adults in the form of coffee, tea, and soft drinks with caffeine content ranging from $40 \mathrm{mg}$ in a 12-ounce cola drink to about $150 \mathrm{mg}$ in an 8-ounce cup of brewed coffee. ${ }^{1}$ Today, specialty coffee drinks and caffeinated energy drinks (EDs) are especially popular, particularly among college students. These drinks frequently come in larger servings

\footnotetext{
${ }^{1}$ Wright Center for Clinical and Translational Research, Virginia Commonwealth University, Richmond, Virginia.

${ }^{2}$ Psychology Department, Virginia Commonwealth University, Richmond, Virginia.

${ }^{3}$ Virginia Institute for Psychiatric and Behavioral Genetics, Virginia Commonwealth University, Richmond, Virginia.

Departments of ${ }^{4}$ Psychiatry, and ${ }^{5}$ Human and Molecular Genetics, Virginia Commonwealth University, Richmond, Virginia.

${ }^{6}$ Biostatistics Department, Virginia Commonwealth University, Richmond, Virginia.

${ }^{7}$ Psychology Department, Institute for Women's Health, Virginia Commonwealth University, Richmond, Virginia.
} 
and with substantially more caffeine per serving than traditional caffeinated beverages (e.g., $300 \mathrm{mg}$ of caffeine in 16-ounce brewed coffee and $110 \mathrm{mg}$ in a $12-\mathrm{oz}$ Red Bull ED). ${ }^{1}$ Often, EDs contain not only caffeine, but also large amounts of sugar, a variety of vitamins, and other stimulants, including guarana, which is pharmacologically similar to caffeine. A single can of an ED typically has the equivalent amount of caffeine as 3-5 cans of soda. Further, in both coffee drinks and EDs, the actual amounts of the ingredients are not always provided in the labeling and vary across individual servings. ${ }^{12,13}$

ED companies target consumers in the 18-34 year-old population, ${ }^{14}$ and EDs are especially popular among college students looking for ways to stay awake longer and focus in high-pressure situations. ${ }^{15,16}$ Also, ED use is part of the college social culture with more than one-third of college students reporting past-year consumption of alcohol mixed with EDs. ${ }^{17}$ This is particularly troubling as many substance use disorders manifest during the late teens and early 20 s, an age when many are attending college. ${ }^{18}$

Since the introduction of these heavily caffeinated drinks, retrospective studies in college students have shown that ED use is correlated with a variety of adverse consequences. Specifically, ED users consume higher quantities of alcohol and with greater frequency than nonED users. ${ }^{19,20}$ In addition, weekly ED users are more likely to meet criteria for alcohol dependence than their peers. ${ }^{20}$ ED consumption is also positively associated with tobacco, marijuana, and nonmedical prescription drug use; unsafe sexual behavior; other risky behaviors (e.g., fighting, not wearing a seatbelt); and poor nutrition. ${ }^{21-23}$

The popularity of EDs and the public health risks associated with their use in combination with alcohol have made EDs the focus of many, if not most, studies of caffeine use in college students. As a result, much less attention has been given to other sources of caffeine (e.g., coffee, tea, soda). However, some of these other beverages (e.g., Starbucks grande coffee, Starbucks expresso, and Mountain Dew Game Fuel) now have caffeine content (mg) similar to EDs. Therefore, it is critical to evaluate whether the associations with adverse health behaviors are unique to ED or instead reflect a general relationship between caffeine consumption and risky health behaviors. This study evaluated patterns of caffeine use, in general, and ED use, specifically, in a representative sample of college freshmen. We predicted that ED use would be more strongly associated with other substance use and problem behaviors compared to caffeine use in general, especially among regular caffeine users. We also explored the effect of gender on caffeine use and the associated adverse health effects.

\section{Methods}

\section{Sample}

Participants were incoming freshmen at a large, public, urban university in the mid-Atlantic region who enrolled in the "Spit for Science" (S4S) longitudinal study to evaluate genetic, environmental, and developmental influences on alcohol use and health-related outcomes. ${ }^{24}$ Eligible students were at least 18 years and freshmen at the university at the time of the survey. Fifty-seven percent (2056 students) of the freshman class participated in the survey during the fall of their first year. Forty-five students were excluded from this research because they did not provide gender and/or race data, and 53 were excluded because they did not provide a response to the survey question "Do you drink any caffeinated beverages?," leaving a final study sample of 1958 students.

\section{Procedure}

Students completed the 30-minute S4S online survey that asked about personality traits, behavior, family/ peer relationships, health, and experiences growing up. Participation in the study was voluntary, and all data collected were coded for confidentiality. ${ }^{24}$ All research activities were approved by the university's Institutional Review Board.

\section{Survey measures}

Any caffeine use. Participants answering yes to the question "Do you drink any caffeinated beverages" were asked about past month frequency of use (typical days/ week) for six types of caffeinated beverages [coffee, hot/ cold tea, sodas, EDs, energy shots, other beverages (e.g., vitamin/energy water, hot chocolate)] and caffeinecontaining over-the-counter medications. For this study, any caffeine users (ACUs) were students who reported consuming a caffeinated product at least 1 day/week during the past month, while ED users were students reporting ED and/or energy shot use on average 1 day/week in the past month. Based on the literature, daily caffeine users (DCUs) were those who reported consuming any one caffeinated product every day, and regular ED users were those drinking EDs or energy shots on average two or more days per week. ${ }^{20,21,25,26} \mathrm{ACU}$ was compared to daily/regular use to distinguish between casual users and habitual consumers (i.e., those most likely to be dependent on caffeine).

Alcohol use and problems. Past-month frequency (number of days they consumed alcohol) and quantity (average drinks per drinking day) were assessed. Total alcohol consumed was calculated by multiplying days used by average drinks per drinking day $(\mathrm{Q} \times \mathrm{F})$. Symptoms of alcohol dependence were assessed with questions adapted from the Semi-Structured Assessment of the Genetics of Alcoholism. ${ }^{27}$

Other drug use. Participants reported (yes or no) whether they had used any of five classes of drugs (marijuana, sedatives, stimulants, cocaine, and opioids) at least six times during their lifetime for nonmedical use. Also, lifetime (>100 cigarettes) cigarette smoking was assessed. 


\section{Analyses}

For categorical variables, chi-square tests or Fisher's exact tests, when appropriate, were used for caffeine group comparisons. For continuous variables, a nonparametric Mann-Whitney $U$-test (Wilcoxon rank-sum test) was used to compare caffeine groups. Odds ratios (OR) with $95 \%$ confidence intervals (CIs) were calculated separately in men and women to examine patterns of caffeine use and adverse health behaviors. No adjustments were made for multiple comparisons, and $p<0.05$ was considered statistically significant.

\section{Results}

Participants $(n=1958)$ had a mean age of 18.5 years $(\mathrm{SD}=0.61)$, and over half $(61.3 \%, 1200)$ were female. More than half of students reported their race as Caucasian (52.7\%), with 19.4\% African American, 15.2\% Asian, and $12.7 \%$ other races/ethnicities. Importantly, the sample was demographically similar to the general population of undergraduate students at the university. ${ }^{24}$

\section{Patterns of caffeine use}

Eighty percent of participants reported current caffeine use, with women more likely to report use than men $(85 \%$ vs. $71 \%, p<0.0001$; Table 1). Further, there were significant differences by gender in the types of caffeinated beverages consumed. Men were more likely to report consuming EDs ( $p=0.0121)$, and women were more likely to report drinking coffee, tea, soda, and "other caffeinated beverages" ( $p \leq 0.0416$ for all). Almost one-fourth (24\%) of students regularly consumed caffeine; $25 \%$ of women and $22 \%$ of men reported DCU. Finally, $\sim 1$ in 10 students $(9 \%)$ reported regular ED use: $8 \%$ of women and $10 \%$ of men.

\section{Associations between caffeine use and adverse health behaviors \\ Caffeine users.}

Any caffeine use. Overall, ACUs were more likely to use alcohol compared to noncaffeine users (64\% vs. $59 \%, p=0.0046)$, and they drank more alcohol on the days they reported drinking $(p=0.0040)$. However, there was no significant difference in drug use or smoking between caffeine and noncaffeine users.
Gender differences in alcohol use and alcohol-related problems were evident. Women who used any caffeine weekly were more likely to use alcohol (64\% vs. 53\%, $p=0.0297$ ), and, among drinkers, use more alcohol $(p=0.0087)$ than female students who did not use caffeine. Also, significantly more female ACUs reported drinking more alcohol than they intended than female students who did not use caffeine $(\mathrm{OR}=2.14,95 \% \mathrm{CI}$ : 1.25-3.67, Fig. 1). Conversely, male ACUs were less likely than noncaffeine users to report alcohol-related problems including giving up important activities to drink, spending so much time drinking/recovering from drinking they had little time for anything else, continuing to drink despite problems, and experiencing withdrawal symptoms (ranging from $\mathrm{OR}=0.32,95 \% \mathrm{CI}$ : $0.15-0.67$ to $\mathrm{OR}=0.54,95 \% \mathrm{CI}: 0.34-0.88)$.

For other substance use, when evaluated by gender, only one difference was found. Female ACUs were more likely to report marijuana use than women who did not use caffeine $(\mathrm{OR}=1.58,95 \% \mathrm{CI}$ : 1.06-2.36).

Daily caffeine use. DCUs were more likely to consume alcohol (69\% vs. $62 \%, p=0.0010)$, and among drinkers, reported using more alcohol compared with non-DCUs $(p<0.0001)$. Further, more DCUs reported alcohol-related problems including strong desire to drink, alcohol tolerance, drinking more than intended, and becoming drunk without intending to than did nonDCUs (ranging from $\mathrm{OR}=1.36,95 \% \mathrm{CI}$ : $1.00-1.85$ to $\mathrm{OR}=1.71,95 \% \mathrm{CI}: 1.13-2.60)$. Also, DCUs were more likely to report marijuana, sedative, stimulant, and tobacco use than non-DCUs (ranging from $\mathrm{OR}=1.30$, 95\% CI: $1.04-1.63$ to $\mathrm{OR}=2.28,95 \% \mathrm{CI}: 1.67-3.12$ ).

When examined by gender, female DCUs differed from nondaily users on only one alcohol variable: amount of alcohol consumed $(p=0.0166)$. There was a similar pattern in male students $(p=0.0013)$. Also, significantly more male DCUs reported developing tolerance $(\mathrm{OR}=1.80,95 \% \mathrm{CI}: 1.18-2.76$, Fig. 1) and drinking more than they intended $(\mathrm{OR}=2.00,95 \% \mathrm{CI}$ : 1.28-3.12) than non-DCUs.

Significantly more women who used caffeine daily reported marijuana, sedative, stimulant, and tobacco use than female nondaily users (ranging from $\mathrm{OR}=$ 1.46, 95\% CI: $1.09-1.95$ to $\mathrm{OR}=2.38,95 \% \mathrm{CI}: 1.54$

Table 1. Caffeine Use by Type in College Females and Males

\begin{tabular}{lcccc}
\hline & Total $\%(\mathrm{n})(\mathrm{n}=1958)$ & Female $\%(\mathrm{n})(\mathrm{n}=1200)$ & Male \% $(\mathrm{n})(\mathrm{n}=758)$ & $\mathrm{p}$ \\
\hline Any caffeine & $80(1560)$ & $85(1019)$ & $71(541)$ & $<0.0001$ \\
Coffee & $52(1011)$ & $60(714)$ & $39(297)$ & $<0.0001$ \\
Tea & $54(1062)$ & $60(721)$ & $45(341)$ & $<0.0001$ \\
Soda & $66(1286)$ & $67(809)$ & $63(477)$ & 0.0416 \\
Energy drink & $16(313)$ & $14(172)$ & $19(141)$ & 0.0121 \\
Energy shot & $4(78)$ & $4(43)$ & $5(35)$ & 0.2544 \\
Other & $18(350)$ & $20(238)$ & $15(112)$ & 0.0044 \\
Caffeinated medications & $6(122)$ & $7(87)$ & $5(35)$ & 0.0189 \\
\hline
\end{tabular}



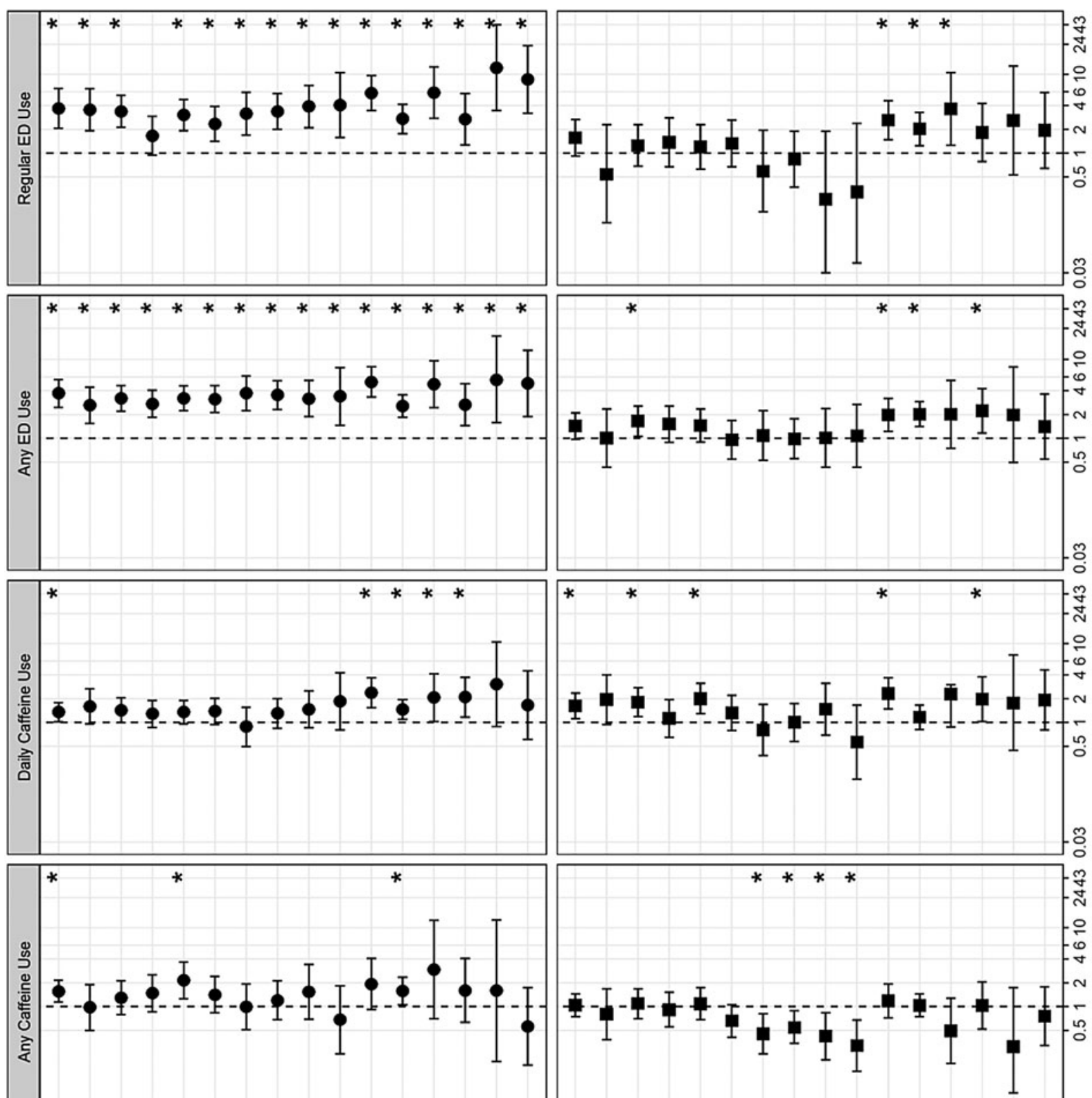

预。응

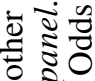

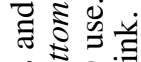

แัง

철 흠

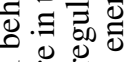
흥 छे

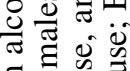

हี

응 氖国

을 完

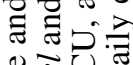

๑ ญ 증

ำ

ᄋ ฐ

《完它

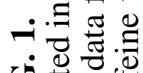

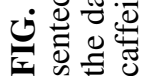


3.69, Fig. 1). In male college students, DCUs were more likely to use stimulants and tobacco compared with nonDCUs (OR $=1.97,95 \% \mathrm{CI}: 1.03-3.79$ and $\mathrm{OR}=2.32$, 95\% CI: 1.47-3.67, respectively).

\section{ED users.}

Any ED use. ED users were significantly more likely to report alcohol use $(78 \%$ vs. $60 \%, p<0.0001)$ and report more alcohol use $(p<0.0001)$ than non-ED users. ED users were also more likely to endorse all problem alcohol behaviors (ranging from OR $=1.87,95 \%$ CI: 1.20 2.92 to $\mathrm{OR}=2.43,95 \% \mathrm{CI}: 1.83-3.24$ ) and all categories of nonmedical drug use (ranging from $\mathrm{OR}=2.36,95 \%$ CI: $1.85-3.00$ to $\mathrm{OR}=3.52,95 \%$ CI: $2.01-6.16)$ than non-ED users.

Female ED users reported higher frequency ( $84 \%$ vs. $58 \%, p<0.0001)$ and quantity $(p<0.0001)$ of alcohol use compared with non-ED users. As shown in Figure 1, female ED users were two to three times more likely to endorse each of the nine symptoms of problem drinking than women who did not use EDs (OR $\geq 2.62,95 \%$ CI: 1.46-7.88). Conversely, there was no difference in alcohol use between male ED users and nonusers, and male ED users were more likely than non-ED users to endorse only one of nine problem drinking symptoms, tolerance $(\mathrm{OR}=1.65,95 \%$ CI: 1.06-2.57).

Female ED users were more likely to endorse use of all five drug classes than non-ED users (ranging from $\mathrm{OR}=2.57,95 \% \mathrm{CI}: 1.85-3.56$ to $\mathrm{OR}=4.95,95 \% \mathrm{CI}$ : 1.88-12.99). However, for men, this pattern was only found for marijuana and stimulants $(\mathrm{OR}=2.01,95 \%$ CI: $1.40-2.90$ and $\mathrm{OR}=2.23,95 \%$ CI: $1.16-4.29$, respectively). For cigarette smoking, both female and male ED users reported smoking more frequently than non-ED users $(\mathrm{OR}=5.18,95 \% \mathrm{CI}: 3.32-8.10$ and $\mathrm{OR}=1.98$, 95\% CI: $1.23-3.19$, respectively).

Regular ED use. Overall, significantly more regular ED users reported alcohol use than those who did not use ED regularly (79\% vs. $61 \%, p<0.0001$ ), and they consumed more alcohol $(p<0.0001)$. In addition, they were more likely to report seven problem alcohol-related behaviors (ranging from $\mathrm{OR}=1.84,95 \% \mathrm{CI}$ : $1.07-3.15$ to $\mathrm{OR}=2.25,95 \% \mathrm{CI}: 1.56-3.25)$ and nonmedical drug use (ranging from $\mathrm{OR}=2.28,95 \% \quad \mathrm{CI}: \quad 1.30-4.01$ to $\mathrm{OR}=6.28,95 \%$ CI: 2.44-16.18) than nonregular ED users.

Women who regularly used EDs were significantly more likely to report alcohol use $(85 \%$ vs. $60 \%$, $p<0.0001$ ), and they reported drinking more alcohol than nonregular ED users $(p<0.0001)$. Further, women who used ED regularly were significantly more likely to endorse all but one (wanting to cut down) of the symptoms of problem drinking compared to nonregular ED users (ranging from $\mathrm{OR}=2.36,95 \% \mathrm{CI}$ : $1.41-3.93$ to $\mathrm{OR}=4.08,95 \%$ CI: $1.58-10.54$, Fig. 1). These patterns were not seen in male students.
Similarly, female students who regularly used EDs also reported significantly more marijuana, sedative, stimulant, cocaine, opioid, and tobacco use than nonregular $\mathrm{ED}$ users (ranging from $\mathrm{OR}=2.69,95 \% \mathrm{CI}$ : $1.27-5.72$ to $\mathrm{OR}=12.12,95 \%$ CI: $3.45-42.65$ ). In men, regular ED users were more likely to report only marijuana, sedative, and tobacco use (ranging from $\mathrm{OR}=2.03,95 \% \mathrm{CI}: 1.24-3.30$ to $\mathrm{OR}=3.64,95 \% \mathrm{CI}$ : 1.26-10.50) compared with nonusers.

\section{Discussion}

The explosive growth in the ED market, especially among college students, has increased the focus on caffeine use and the associated adverse health behaviors in this population. This study found caffeine use in general, and ED use in particular, was common in college students. For women, but not men, ACU was associated with alcohol use and some alcohol-related problems. A more robust relationship was seen between DCUs and other substance use, including cigarettes, alcohol, and nonmedical drugs, in women; however, this pattern was not seen in male students. Even more striking, in women, both any and regular ED use were associated with alcohol, nonmedical drug, and tobacco use along with problem alcohol behaviors, and that was true for every substance and behavior assessed. While more male students reported ED use, the associations between ED use and adverse health behaviors were not found.

Our study found the majority of students at one large, urban university consumed caffeine on a regular basis, with approximately one-fourth reporting daily use. Further, almost one in five students reported recent ED use, and almost 1 in 10 reported regular use. While overall prevalence of caffeine use was similar to published literature, which found more than three-fourths of college students consumed caffeine, ${ }^{1,5,6}$ the prevalence of ED use in our population was somewhat lower than often reported for college students $(\sim 40 \%)^{22,28,31,32}$ and was more consistent with that found for high school students, (20$30 \%)^{29,30}$ This was not surprising as many current study participants completed the survey at the beginning of their freshman year, and ED use is known to increase during college. ${ }^{19}$ Further, women were significantly more likely to consume any-source caffeine, specifically coffee, tea, soda, and "other" caffeinated beverages, than men. Only ED use was more prevalent in male students. Such patterns are generally consistent with published literature. ${ }^{19,31,32,33}$ One interesting distinction from previous research is the suggestion of increased caffeine use by female students compared to male students. ${ }^{34}$ However, these data must be interpreted with caution as no assessments of actual caffeine intake were done.

This study data affirm the consistent findings that ED use is associated with alcohol, nonmedical drug, and cigarette use in addition to symptoms of alcohol dependence. ${ }^{19-22,32}$ 
Combined with findings from Miller ${ }^{21}$ and Thombs ${ }^{35}$ that showed college students who consume EDs are more likely to engage in a variety of risky physical and sexual behaviors, these data indicate ED use may be part of a pattern of sensation seeking seen in students with risk-taking personalities. ${ }^{19}$ In the subgroup of students who mix alcohol and EDs, there is evidence that caffeine attenuates the depressant effects of alcohol and subjective feelings of drunkenness that cause some people to stop drinking. This in turn may lead to heavier drinking in college students who use the two beverages together. ${ }^{35,36}$

In our research, the relationship between ED use and adverse health behaviors was found with both any ED use and more frequent $\mathrm{ED}$ use. While this suggests that precise measures of ED consumption are not necessary to identify students at risk for ED-associated problems, the literature regarding this is inconclusive. ${ }^{26,31}$ Investigations into potential dose-response relationships between ED use and adverse health behaviors are complicated by inconsistent definitions used to stratify ED use across research. Future investigations about the relationship between ED use and adverse health behaviors could benefit from a standard method for quantifying ED use.

Traditionally, EDs had relatively large amounts of caffeine compared with other caffeinated beverages, and most studies in college students focused on adverse health behaviors associated with ED use, ignoring other sources of caffeine intake. Today, there are many specialty coffee drinks and even sodas that contain similar amounts of caffeine as EDs. This study found daily any-source caffeine use was associated with increased tobacco, nonmedical drug, and alcohol use and alcohol-related problems, although the data were not as robust as that seen with ED use. The effects of caffeine on adverse health behaviors were dose dependent, and patterns with ACU were less remarkable than those seen with DCU. Because present study data are cross-sectional, factors contributing to such correlations cannot be teased apart.

These data are especially striking when analyzed by gender. ED use was associated with other substance use and alcohol-related problems only in women. As described above, in women, the relationship between ED use and associated adverse health behaviors was consistent regardless of the frequency of ED use. When anysource caffeine data were examined separately in men and women, we found female students were disproportionately affected by caffeine in general, although the data were less robust than those seen with EDs. This is one of the first studies to show such a substantive gender disparity, which is likely the result of a combination of factors. There are gender differences reported in the metabolism and physiologic responses to caffeine. Men metabolize caffeine at a higher rate than women, ${ }^{37}$ resulting in decreased clearance, ${ }^{38}$ perhaps increased exposure to caffeine, and subsequently, the associated adverse health behaviors. Also, while no assessment of estradiol was made in this study, prior research has shown that increased circulating estradiol augments the physiologic and subjective effects associated with caffeine. ${ }^{39}$ This too may impact the higher incidence of substance use and problem alcohol behaviors seen in female college students compared with male students. These variables should be considered in future research that evaluates gender differences in adverse behaviors associated with caffeine use.

In addition to potential gender-related pharmacokinetic effects, certain psychosocial factors must also be considered when examining adverse health behaviors associated with caffeine use. Caffeine use, particularly in the form of EDs, has been associated with psychosocial factors such as impulsivity and risk-taking, ${ }^{40,41}$ and it may be these traits that drive the relationship between caffeine use and other substance use and alcohol-related problems that we saw in female college students in this research. In fact, Spangler et al. recently reported increased alcohol mixed with ED use in female college students compared with male students. ${ }^{42}$ Finally, the wide variability in individual responses, both physiologically and psychologically, to caffeine cannot be discounted and may explain the differences in adverse health behaviors seen in this research. The data from this research are compelling because previous work shows heavy caffeine use may predict other problem behaviors including ones that can extend into adulthood. In a study of fourth year college students, Arria showed that, independent of other risk factors, daily and weekly ED use was significantly associated with alcohol dependence. ${ }^{20}$ Further, genetic studies found an association in adult twins between lifetime caffeine use, toxicity, and dependence and development of substance use disorders including alcohol dependence, marijuana use, and cocaine abuse/dependence. ${ }^{43}$

Public health implications of this research are considerable. Caffeine use, from EDs, coffee, soda, and tea, is common on college campuses and is associated with increased alcohol use. As college administrators grapple with ways to address alcohol use on campus, reports of DCU may help identify students most likely to drink larger amounts of alcohol. Screening to identify regular or DCU may be a valuable indirect way to identify students at risk for other substance use and related problem behaviors. Such screening may be more likely to elicit accurate data because there are fewer stigmas associated with caffeine use compared wih alcohol or illicit drug use. Students reporting regular caffeine use may be at higher risk for not only increased alcohol use and dependence symptoms, but also increased nonmedical drug and cigarette use, and these students may warrant particular attention with regard to interventions aimed at promoting healthy behaviors in college students.

Similar to telescoping seen in women with a variety of substance use disorders, ${ }^{44}$ female students who use caffeine appear to be at greater risk for associated adverse health 
behaviors compared with male students who use caffeine. ${ }^{42}$ While this may be due to differences in caffeine pharmacokinetics between women and men, all women are not affected equally, and future research should try to better define those students at highest risk for problems associated with caffeine use. The increased incidence of alcoholrelated problem behaviors in male students who did not report ACU is an interesting paradox. While the results may be due to chance, the gender effects on adverse behaviors associated with caffeine use seen in this study suggest that more research is warranted. Further, our data suggest that gender specific interventions may be useful to address the disturbing alcohol and drug use patterns associated with caffeine use in female college students. This study underscores the importance of looking at not only EDs, but also daily use of any-source caffeine, in future research. Finally, this work points to the need for additional research that looks at disentangling the genetic and environmental factors that contribute to adverse health behaviors associated with caffeine use and especially focuses on the differences in outcomes in male and female students.

Present study findings must be considered in the context of several limitations. First, survey data focused only on frequency of use of different caffeine-containing beverages, which may not accurately capture actual caffeine consumption. In fact, the conclusion that the association between any-source caffeine and adverse health behaviors was not as strong as that seen with EDs may be explained by this particular limitation. For the analyses of general caffeine use, all types of caffeinated beverages were examined together. Therefore, the inclusion of caffeinated beverages containing low levels of caffeine, without quantity data, in the analyses may dilute the actual effects of caffeine on the behavioral outcomes assessed. While the methodology for the ED analyses were the same, the variation among a single type of caffeine-containing beverage was likely less, and its impact on the outcomes was likely less. Second, this study only collected data about past-month use and may not accurately reflect variations in more typical or heaviest caffeine use over time. Third, the data were retrospective and relied on self-report, both of which could have introduced bias into our results. Finally, this work was done at a single University, and the results may not be generalizable to other institutions or populations.

\section{Acknowledgments}

Spit for Science has been supported by Virginia Commonwealth University, P20 AA017828, R37AA011408, K02AA018755, and P50 AA022537 from the National Institute on Alcohol Abuse and Alcoholism, UL1RR031990 from the National Center for Research Resources and National Institutes of Health Roadmap for Medical Research, and UL1TR000058 from the National Center for Advancing Translational Science.
We would like to thank the Spit for Science participants for making this study a success, as well as the many University faculty, students, and staff who contributed to the design and implementation of the project. Also, we would like to thank Brian DiPace for his assistance with the data analyses.

\section{Author Disclosure Statement}

No competing financial interests exist.

\section{References}

1. Mitchell DC, Knight CA, Hockenberry J, Teplansky R, Hartman TJ. Beverage caffeine intakes in the U.S. Food Chem Toxicol. 2014;63:136-142.

2. Branum AM, Rossen LM, Schoendorf KC. Trends in caffeine intake among U.S. children and adolescents. Pediatrics. 2014;133:386-393.

3. Carter AC, Brandon KO, Goldman MS. The college and noncollege experience: A review of the factors that influence drinking behavior in young adulthood. J Stud Alcohol Drugs. 2010;71:742-750.

4. Schulenberg JE, Johnston LD, O'Malley PM, Bachman JG, Miech RA, Patrick ME. Monitoring the Future national survey results on drug use, 1975-2017: Volume II, College students and adults ages 19-55. Ann Arbor: Institute for Social Research, The University of Michigan; 2018.

5. McIlvain GE, Noland MP, Bickel R. Caffeine consumption patterns and beliefs of college freshmen. Am J Health Educ. 2011;42:235-244.

6. Norton TR, Lazev AB, Sullivan MJ. The "buzz" on caffeine: Patterns of caffeine use in a convenience sample of college students. J Caffeine Res. 2011;1:35-44.

7. Mahoney CR, Giles GE, Marriott BP, et al. Intake of caffeine from all sources and reasons for use by college students. Clin Nutr. 2018 [Epub ahead of print]; DOI: 10.1016/j.clnu.2018.04.004.

8. Committee on Nutrition and the Council on Sports Medicine and Fitness. Sports drinks and energy drinks for children and adolescents: Are they appropriate? Pediatrics. 2011;127:1182-1189.

9. U.S. Food and Drug Administration, 2012. letter from Jeanne Ireland, Assistant Commissioner for Legislation, FDA, to Senator Richard J. Durbin (August 10, 2012). $<$ www.durbin.senate.gov/public/index.cfm/files/serve? File_id=17eadaa1-85e7-4ceb-a827-be244fbddfa5> (Last accessed April 30, 2018).

10. Heckman MA, Weil J, Gonzalez de Mejia E. Caffeine (1, 3, 7-trimethylxanthine) in foods: A comprehensive review on consumption, functionality, safety, and regulatory matters. J Food Sci. 2010;75:R77-R87.

11. American Psychiatric Association. Diagnostic and statistical manual of mental disorders. 5th edition ed. Washington, DC; 2013.

12. Reissig CJ, Strain EC, Griffiths RR. Caffeinated energy drinks-A growing problem. Drug Alcohol Depend. 2009;99:1-10.

13. McCusker RR, Goldberger BA, Cone EJ. Caffeine content of specialty coffees. J Anal Toxicol. 2003;27:520-522.

14. Heckman MA, Sherry K, De Mejia EG. Energy drinks: An assessment of their market size, consumer demographics, 
ingredient profile, functionality, and regulations in the united states. Compr Rev Food Sci Food Saf. 2010;9: 303-317.

15. Attila S, Çakir B. Energy-drink consumption in college students and associated factors. Nutrition. 2011;27: 316-322.

16. Malinauskas BM, Aeby VG, Overton RF, Carpenter-Aeby T, Barber-Heidal K. A survey of energy drink consumption patterns among college students. Nutr J. 2007;6:35.

17. Marczinski CA, Fillmore MT. Energy drinks mixed with alcohol: What are the risks? Nutr Rev. 2014;72 Suppl 1: 98-107.

18. Kessler RC, Berglund P, Demler O, Jin R, Merikangas $\mathrm{KR}$, Walters EE. Lifetime prevalence and age-of-onset distributions of DSM-IV disorders in the national comorbidity survey replication. Arch Gen Psychiatry. 2005;62: 593-602.

19. Arria AM, Caldeira KM, Kasperski SJ, et al. Increased alcohol consumption, nonmedical prescription drug use, and illicit drug use are associated with energy drink consumption among college students. J Addict Med. 2010;4:74.

20. Arria AM, Caldeira KM, Kasperski SJ, Vincent KB, Griffiths RR, O'Grady KE. Energy drink consumption and increased risk for alcohol dependence. Alcohol Clin Exp Res. 2011;35:365.

21. Miller KE. Energy drinks, race, and problem behaviors among college students. J Adolesc Health. 2008;43: 490-497.

22. Poulos NS, Pasch KE. Energy drink consumption is associated with unhealthy dietary behaviours among college youth. Perspect Public Health. 2015;135:316-321.

23. O'Brien MC, McCoy TP, Rhodes SD, Wagoner A, Wolfson M. Caffeinated cocktails: Energy drink consumption, high-risk drinking, and alcohol-related consequences among college students. Acad Emerg Med. 2008;15: 453-460.

24. Dick DM, Nasim A, Edwards AC, et al. Spit for science: Launching a longitudinal study of genetic and environmental influences on substance use and emotional health at a large US university. Front Genet. 2014;5:47.

25. Polak K, Dillon P, Koch JR, Miller WGJ, Thacker L, Svikis D. Energy drink use is associated with alcohol and substance use in eighth, tenth, and twelfth graders. Prev Med Rep. 2016;4:381-384.

26. Spierer DK, Blanding N, Santella A. Energy drink consumption and associated health behaviors among university students in an urban setting. J Community Health. 2014;39:132-138.

27. Bucholz KK, Cadoret R, Cloninger CR, et al. A new, semi-structured psychiatric interview for use in genetic linkage studies: A report on the reliability of the SSAGA. J Stud Alcohol. 1994;55:149-158.

28. Skewes MC, Decou CR, Gonzalez VM. Energy drink use, problem drinking and drinking motives in a diverse sample of alaskan college students. Int J Circumpolar Health. 2013;72.

29. Azagba S, Langille D, Asbridge M. An emerging adolescent health risk: Caffeinated energy drink consumption patterns among high school students. Prev Med. 2014; 62:54-59.
30. Terry-McElrath YM, O’Malley PM, Johnston LD. Energy drinks, soft drinks, and substance use among united states secondary school students. J Addict Med. 2014;8:6-13.

31. Velazquez CE, Poulos NS, Latimer LA, Pasch KE. Associations between energy drink consumption and alcohol use behaviors among college students. Drug Alcohol Depend. 2012;123:167-172.

32. Miller KE. Wired: Energy drinks, jock identity, masculine norms, and risk taking. J Am Coll Health. 2008; 56:481-490.

33. Pettit ML, DeBarr KA. Perceived stress, energy drink consumption, and academic performance among college students. J Am Coll Health. 2011;59:335-341.

34. Landrum RE. College students' use of caffeine and its relationship to personality. Coll Stud J. 1992;26:151-155.

35. Thombs DL, O'Mara RJ, Tsukamoto M, et al. Event-level analyses of energy drink consumption and alcohol intoxication in bar patrons. Addict Behav. 2010;35:325-330.

36. Ferreira SE, de Mello MT, Pompeia S, de SouzaFormigoni ML. Effects of energy drink ingestion on alcohol intoxication. Alcohol Clin Exp Res. 2006;30:598-605.

37. Rasmussen BB, Brix TH, Kyvik KO, Brosen K. The interindividual differences in the 3-demthylation of caffeine alias CYP1A2 is determined by both genetic and environmental factors. Pharmacogenetics. 2002;12:473-478.

38. White JRJ, Padowski JM, Zhong Y, et al. Pharmacokinetic analysis and comparison of caffeine administered rapidly or slowly in coffee chilled or hot versus chilled energy drink in healthy young adults. Clin Toxicol. 2016;54:308-312.

39. Temple JL, Ziegler AM. Gender differences in subjective and physiological responses to caffeine and the role of steroid hormones. J Caffeine Res. 2011;1:41-48.

40. Miller KE, Dermen KH, Lucke JF. Caffeinated energy drink use by U.S. adolescents aged 13-17: A national profile. Psychol Addict Behav. 2018;32:647-659.

41. Meredith SE, Sweeney MM, Johnson PS, Johnson MW, Griffiths RR. Weekly energy drink use is positively associated with delay discounting and risk behavior in a nationwide sample of young adults. J Caffeine Res. 2016;6:10-19.

42. Spangler JG, Song EY, Egan KL, et al. Correlates of alcohol mixed with energy drink use among first year college students: Clinical and research implications. J Caffeine Adenosine Res. 2018;8:107-112.

43. Kendler KS, Myers J, O Gardner C. Caffeine intake, toxicity and dependence and lifetime risk for psychiatric and substance use disorders: An epidemiologic and co-twin control analysis. Psychol Med. 2006;36:1717-1725.

44. Greenfield SF, Back SE, Lawson K, Brady KT. Substance abuse in women. Psychiatr Clin North Am. 2010;33:339-355.

Address correspondence to: Pamela Dillon, PharmD

Wright Center for Clinical and Translational Research Virginia Commonwealth University 1200 E. Clay Street Richmond, VA 23298

E-mail: pmdillon@vcu.edu 